\title{
Cavernous hemangioma in the thymus: a case report
}

\author{
Naoko Ose*, Yuko Kobori, Yukiyasu Takeuchi, Yoshiyuki Susaki, Seiji Taniguchi and Hajime Maeda
}

\begin{abstract}
Cavernous hemangioma is not a neoplasm, but rather a congenital venous malformation with the potential to develop in all parts of the body, though it is very rarely seen in the thymus. We report a case of cavernous hemangioma in the thymus partially resected. A 71-year-old woman presented with pericardial discomfort, and chest computed tomography $(C T)$ showed a left lateral mediastinal mass which was $2.0 \times 1.2 \times 1.8 \mathrm{~cm}$ in size, with border regularity and without calcification. Its interior was partially enhanced. Three-dimensional chest computed tomography image showed a tortuous vessel connecting to the tumor. Surgical resection was performed for the purpose of providing a definitive diagnosis and treatment because a mediastinal tumor such as thymoma or teratoma was suspected. Partial resection of the thymus including the mass was done by utilizing a three-port, left-sided video-assisted thoracic surgery (VATS) approach with hoisting of the third rib with the patient in a spinal position. A wine-colored mass bulging from the surface of the left lobe of the thymus was identified along with the communicating vessel which could only be cut with an energy device. It is considered that thymic partial resection using VATS is a better option for small and non-infiltrative lesions.
\end{abstract}

Keywords: Cavernous hemangioma, Thymus, Surgery, Partial resection, Image analysis system

\section{Background}

Cavernous hemangioma $(\mathrm{CH})$ is not a neoplasm, but rather a congenital venous malformation with the potential to develop in all parts of the body, though it is very rarely seen in the thymus. Here, we report a case of cavernous hemangioma in the thymus that was partially resected using a video-assisted thoracic surgery (VATS) procedure.

\section{Case presentation}

A 71-year-old woman presented with pericardial discomfort while coughing, and chest computed tomography (CT) showed a left lateral mediastinal mass. Although the mass remained unchanged in CT findings 3 months later, surgical resection was recommended because a mediastinal tumor such as thymoma or teratoma was suspected. The anterior mediastinal mass was $2.0 \times 1.2 \times 1.8 \mathrm{~cm}$ in size, with border regularity and without calcification. Its interior was partially enhanced

* Correspondence: naokoose@toneyama.go.jp

Department of General Thoracic Surgery, National Hospital Organization

Toneyama Hospital, 5-1-1 Toneyama, Toyonaka-shi, Osaka 560-8552, Japan
(Fig. 1a), and a tortuous vessel was revealed in the thymus in enhanced CT imaging (Fig. 1b).

Surgical resection was performed for the purpose of providing a definitive diagnosis and treatment. With the patient in a spinal position, partial resection of the thymus including the mass was done by utilizing a threeport, left-sided VATS approach with hoisting of the third rib. A wine-colored mass bulging from the surface of the left lobe of the thymus was identified (Fig. 2a) along with the communicating vessel (Fig. 2b), which could only be cut with an energy device. The operative time was $138 \mathrm{~min}$ and there was only minor blood loss. The patient was discharged on postoperative day 7 without complications.

The size of the excised mass was $2.3 \times 1.3 \times 1.8 \mathrm{~cm}$, and there was no infiltration of the adjacent thymus (Fig. 3a). A histopathological diagnosis of $\mathrm{CH}$ in the thymus was made based on the marked dilated vascular channels full of blood covered with endothelial cells and without atypia (Fig. 3b), and the vessel was included in the mass.
望 Springer

(c) 2016 Ose et al. Open Access This article is distributed under the terms of the Creative Commons Attribution 4.0 International License (http://creativecommons.org/licenses/by/4.0/), which permits unrestricted use, distribution, and reproduction in any medium, provided you give appropriate credit to the original author(s) and the source, provide a link to the Creative Commons license, and indicate if changes were made. 


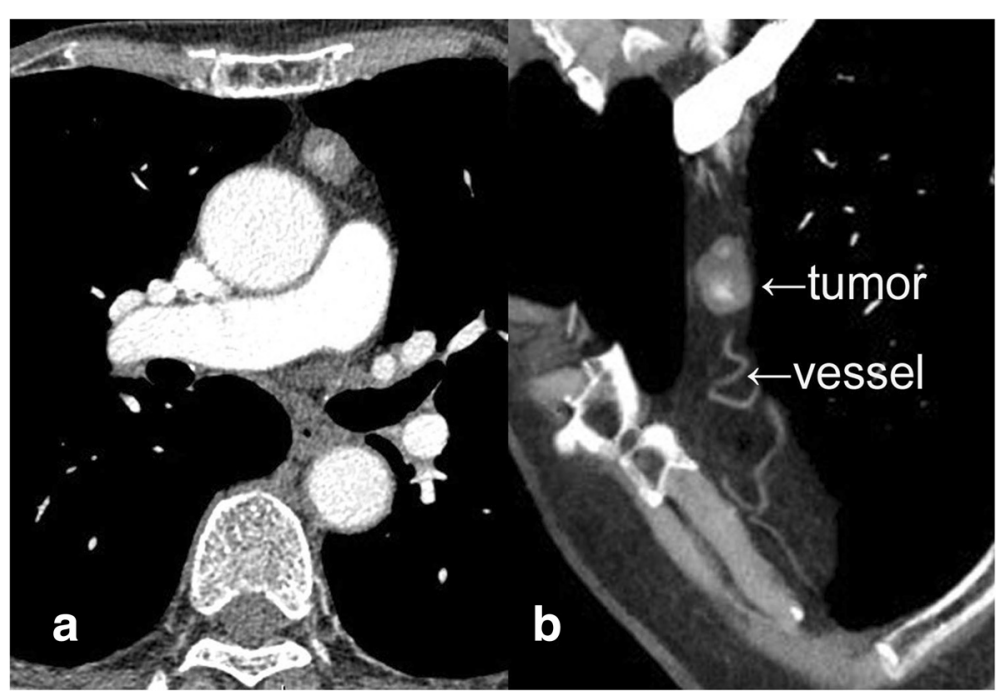

Fig. 1 Enhanced chest computed tomography $(C T)$ scan showing a anterior mediastinal tumor in the left lobe of thymus, $2.0 \times 1.2 \times 1.8 \mathrm{~cm}$ in size, and $\mathbf{b}$ vein running in the thymus in communication with the tumor (arrow)

\section{Discussion}

$\mathrm{CH}$ is not a vascular tumor, but rather a congenital vascular anomaly classified as a venous malformation in the low-flow lesion category by the International Society for the Study of Vascular Anomalies (ISSVA) [1, 2]. This abnormality can occur throughout the whole body, though size and site of origin vary. Some reports have noted its occurrence in patients with a venous aneurysm [3, 4]. Such a vascular anomaly is considered to be the result of local abnormal morphogenesis of normal vascular endothelial cells occurring before birth [2], which then increases in size and exists for the lifetime of the individual without atrophy. Approximately half of the patients with $\mathrm{CH}$ are diagnosed at younger than 20 years old. Histopathological findings generally show cavernous or cystic venous channels with a flat single layer of endothelial cells without atypia or mitosis. The choice of treatment is dependent on the related organ and can include embolization, sclerotherapy, and surgical resection. In cases of resection, the lesion should be completely removed because residual tissue has the potential for recurrence with abnormal vessel dilation or regeneration.

$\mathrm{CH}$ occurs with greater frequency in the liver, accounting for approximately $30 \%$ of known cases, as well as in the brain and skin, whereas there are several reports of mediastinal cases in Japan [5]. Since it was previously thought to be a tumor, a mediastinal $\mathrm{CH}$ is considered to be rare, accounting for $0.5 \%$ or less of all mediastinal tumors [6]. Furthermore, there are only seven reports of cases with a proven thymic origin [3, 4, 7-9].

When occurring in the thymus, a $\mathrm{CH}$ may require resection for diagnosis and treatment, as it is otherwise difficult to distinguish from another type of mediastinal tumor such as a thymoma. Even though it does not generally invade the neighboring tissue, complete resection is desirable, as previously described. Cohen et al. reported that subtotal excision should be chosen if complete resection carries serious

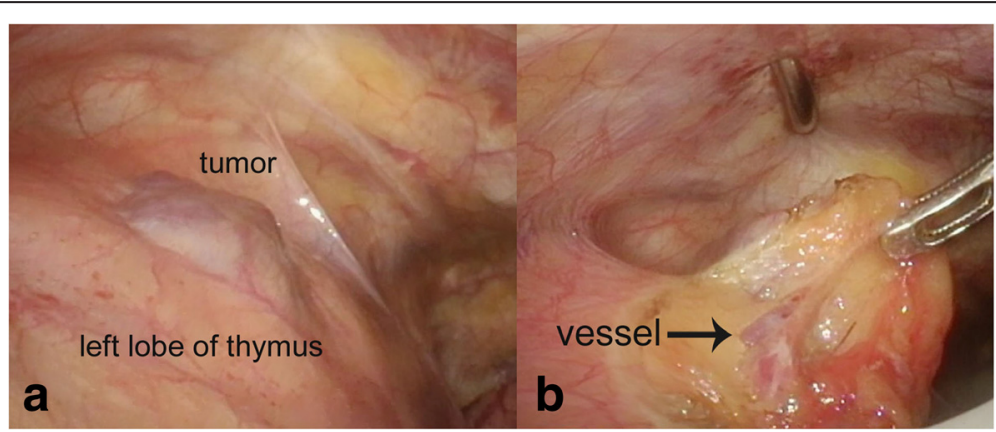

Fig. 2 Intraoperative findings. a Dark red tumor bulging from the surface of the thymus. b The connecting vessel (arrow) was cut using an energy device 


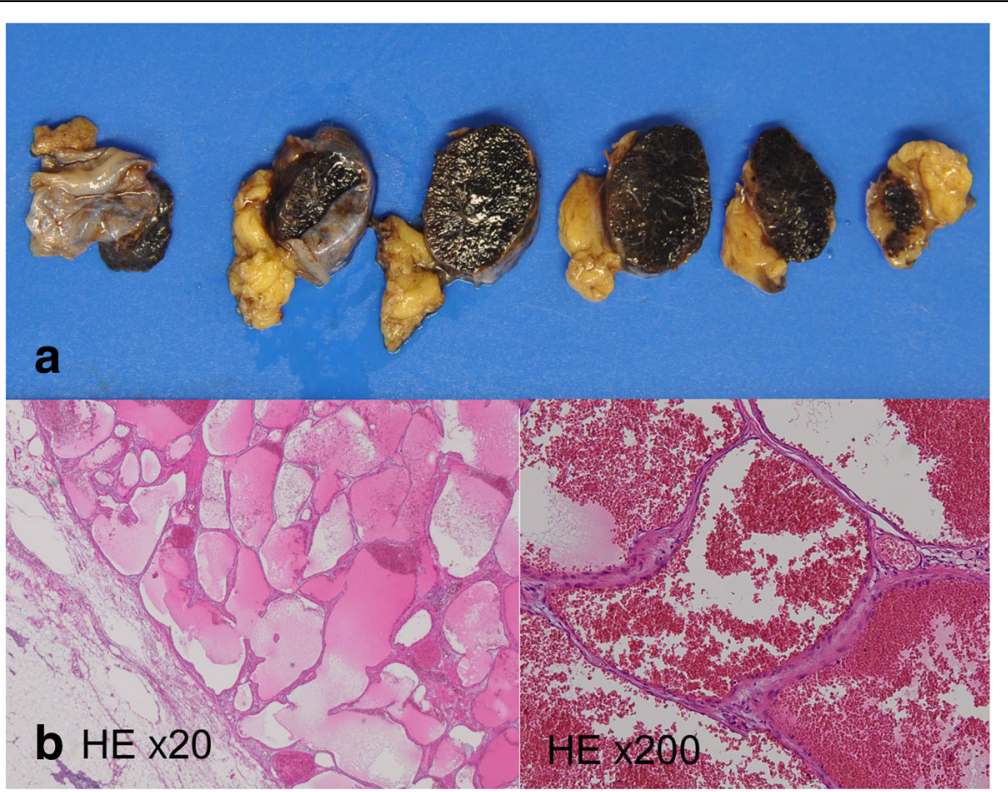

Fig. 3 Histopathological findings of the tumor used for diagnosis of cavernous hemangioma. a There was no invasion of the adjacent thymus. b Hematoxylin and eosin (HE) staining showed a blood vessel ingredient, indicating expansion, and filling with a blood constituent

risk because there was no rapid growth noted in a case of incomplete resection and re-resection can be considered at the time of recurrence [6]. Extirpation by means of a median sternotomy or thoracotomy will be needed in cases with a giant mass [9] or innominate vein aneurism [3, 4]. On the other hand, thymic partial resection using VATS is a better option for small and non-infiltrative lesions, such as seen in the present case.
For accurate diagnosis of $\mathrm{CH}$, magnetic resonance (MR) imaging or ultrasound sonogram are often used to examine the brain, liver, and other organs. The typical imaging manifestation of $\mathrm{CH}$ is popcorn-like lesion with a peripheral hypointense rim so-called hemosiderin rim on T2-weighted MR images. As for mediastinal or lung vascular anomalies, enhanced CT may be very effective, as it can reveal a phlebolith in some cases of venous malformation. No phlebolith was seen in our patient,

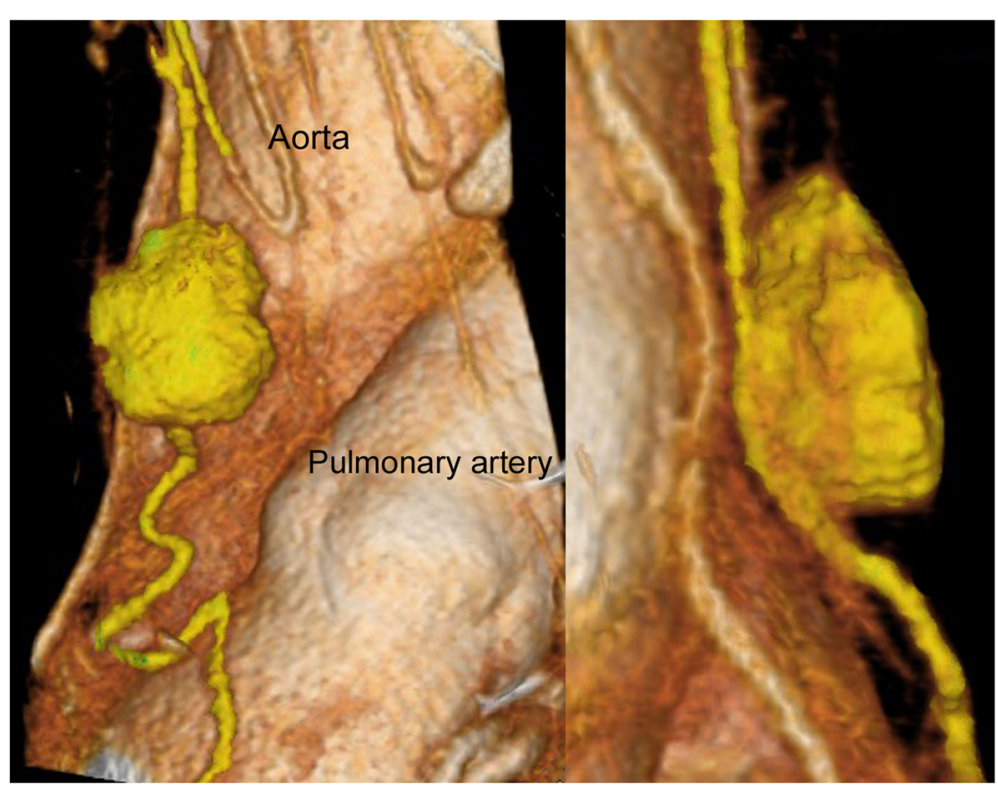

Fig. 4 Three-dimensional chest computed tomography (3D-CT) image showing a tortuous vessel connecting to the tumor 
while the center of the mass was enhanced and a communicating vessel running through the thymus was detected. In addition, findings obtained with a three-dimensional image analysis system (SYNAPSE VINCENT ver. 4.0, Fujifilm Medical Inc., Japan) showed the positional relationship of the tortuous vessel and the mass on the side wall (Fig. 4). We consider that such an image analysis system is helpful for diagnosis of vessel malformation, as seen in the present case.

The mass was resected completely but we intend to follow the present patient to note vessel changes.

\section{Conclusions}

We experienced a rare case of $\mathrm{CH}$ in the thymus. Our experience indicated that enhanced CT and a threedimensional image analysis system would be helpful for diagnosis of vessel malformation and thymic partial resection using VATS would be a better option for small and non-infiltrative lesions.

\section{Consent}

Written informed consent was obtained from the patient for the publication of this report and any accompanying images.

\section{Abbreviations}

$\mathrm{CH}$ : cavernous hemangioma; CT: chest computed tomography;

VATS: video-assisted thoracic surgery.

\section{Competing interests}

The authors declare that they have no competing interests.

\section{Authors' contributions}

NO contributed in writing the paper. YK, YT, YS, ST, and HM helped the attending physician of the presented patient. HM helped in writing the paper and in complete supervision. All authors read and approved the final manuscript.

\section{Acknowledgements}

We thank Hidetoshi Senba for histopathological diagnosis and all staffs at

Toneyama Hospital for treating and caring for this patient.

Received: 24 December 2015 Accepted: 2 February 2016

Published online: 10 February 2016

\section{References}

1. Enjolras O. Classification and management of the various superficial vascular anomalies: hemangiomas and vascular malformations. J Dermatol. 1997;24 701-10

2. Enjolras O, Wassef M, Chapot R. Color atlas of vascular tumors and vascular malformations. New York: Cambridge University press; 2007. p. 1-18.

3. Nakada T, Akiba T, Inagaki T, Morikawa T, Ohki T. Thymic cavernous hemangioma with a left innominate vein aneurysm. Ann Thorac Surg. 2015; 100:320-2.

4. Akiba T, Morikawa T, Hirayama S, Ohki T. Thymic haemangioma presenting with a left innominate vein aneurysm: insight into the aetiology. Interact Cardiovasc Thorac Surg. 2012;15:925-7.

5. Yamazaki A, Miyamoto H, Saito Y, Matsuzawa H, Sakao Y, Anami Y. Cavernous hemangioma of the anterior mediastinum: case report and 50-year review of Japanese cases. Jpn J Thorac Cardiovasc Surg. 2006;54:4-221.

6. Cohen AJ, Sbaschnig RJ, Hochholzer L, Lough FC, Albus RA. Mediastinal hemangiomas. Ann Thorac Surg. 1987;43:656-9.
7. Shen C, Liang Y, Xu H, Liu L, Che G. Cavernous hemangioma of thymus misdiagnosed as thymoma: a case report. World J Surg Oncol. 2014:25:323.

8. Roldán-Baños S, García-Barajas S, León-Medina D. Cavernous hemangioma of the thymus. Arch Bronconeumol. 2012:48:303.

9. Cohen AJ, Chamberlain DW, McKneally MF, Weisbrod GL. Anterior mediastinal mass. Chest. 1993;103:1577-8.

\section{Submit your manuscript to a SpringerOpen ${ }^{\circ}$ journal and benefit from:}

- Convenient online submission

- Rigorous peer review

- Immediate publication on acceptance

- Open access: articles freely available online

- High visibility within the field

- Retaining the copyright to your article 